\title{
Kodlama Etkinliklerinin Öğrencilerin Bilgisayara Yönelik Tutum ve Bilişim Dersine Duyuşsal Katılımlarına Etkisi
}

\author{
Mustafa ESGíl \\ Yüksek Lisans Öğrencisi, Necmettin Erbakan Üniversitesi, Ahmet Keleşoğlu Eğitim Fakültesi, Bilgisayar ve \\ Öğretim Teknolojileri Eğitimi Bölümü \\ mustafaeskilbt@gmail.com \\ Şemseddin GÜNDÜZ \\ Necmettin Erbakan Üniversitesi, Ahmet Keleşoğlu Eğitim Fakültesi, Bilgisayar ve Öğretim Teknolojileri Eğitimi \\ Bölümü \\ semsedding@gmail.com
}

\section{ARAŞTIRMA MAKALESİ/RESEARCH ARTICLE}

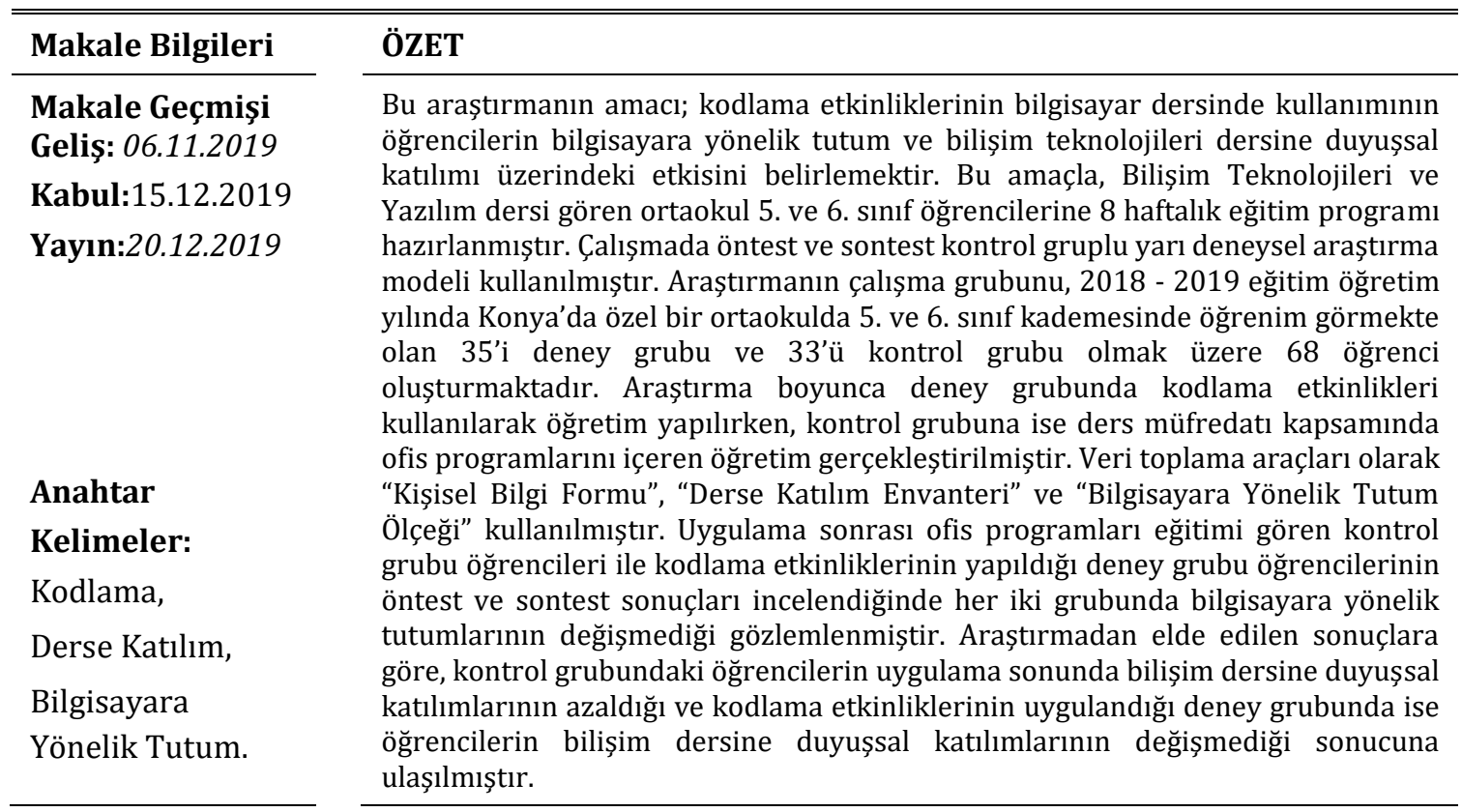


The Effects of Coding Activities on Students' Attitude towards Computer and Their Affective Participation into IT Classes

\begin{tabular}{l} 
Article Info \\
\hline Article History \\
Received:06.11.2019 \\
Accepted:15.12.2019 \\
Published:20.12.2019
\end{tabular}

Keywords:

Coding,

Classroom

Engagement,

Attitude Towards

Computer.

\begin{abstract}
The purpose of this research is to determine the effects of using coding activities in computer course on student's attitudes towards computer and affective participation in informatics course. For this purpose, 8 week training program has been prepared for the 5th and 6th grade students who study Information Technologies and Software at secondary school. In the study, a quasiexperimental research model that carried out a pretest and posttest on control group was used. The research consist of 68 students at 5th and 6th grade at a private school in 2018 - 2019 Academic year and 35 of them are experimental group and 33 of them are control group. During the study, while coding activities were carried out with experimental group, the control group was provided with office programs within the curriculum. "Personal Information Form", Attendance (to the lesson) Inventory" and "Scale for Attitudes Towards Computer" where used as data collection tool. After implementation of the study, when the pretest and posttest results of the control group who were trained with office programming and the experimental group who were trained with coding activities were examined, it was observed that their attitudes towards computer in bath group did not change. According to the result of the study, it was concluded that affective participation in the informatics course of the students who are in the control group decreased and affective participation in the informatics course of the students who are in the experimental group did not change.
\end{abstract}

\section{GİRİ̧}

Günümüzde bilișim teknolojilerinin hızla geliştiği ve toplumlar üzerinde büyük değişimlere neden olduğu bilinmektedir. Sanal ve artırılmış gerçeklik teknolojileri yaygınlaşmış, otomobillere kadar birçok ürün akıllı teknolojiler ile donatılmaya başlanmıştır. Bunun için gelişen teknolojik yeniliklerin sadece kullanıcısı olmak bireyler için artık yetersiz duruma gelmiştir. Değişimin getirdiği birçok yeni bilgi farklı problemlerin ortaya çıkmasına neden olmuştur. Bu problemlere bakış açımız kullanıcıların bilgisayara yönelik tutumu ile doğru orantılı olduğu düşünülmektedir (Sever, 2014). Bilgisayara yönelik tutumun olumlu yönde değişmesi için farklı eğitim etkinlikleri planlanabilmektedir.

Bilgi ve iletişim teknolojilerinin verimli biçimde kullanılabilmesi için bazı ön bilgi ve becerilere gereksinim duyulmaktadır. Bunun nedeni içinde bulunduğumuz yüzyılda bireylerin işlerini yürütmesi ve teknolojik olarak gerekli becerilere sahip olması gerekliliğinin geçmiş yıllara göre artmış olmasıdır (Karakaş, 2015). 21. yüzyılda iş sahibi olmak isteyen bireylerden bilgisayar kullanma ile ilgili yeterlilikler istenmektedir.

$\mathrm{Bu}$ istenen beceriler bilgisayarın meslekler içerisindeki yerinin artmakta olduğunu göstermektedir. Bu becerilerden bazıları; paket programlarına hâkim, algoritmik düşünebilen, dijital dünyadan haberdar olan, sosyal medyayı iyi kullanabilen, gerektiğinde topluma hılı bilgi ulaştırabilen, çalışma ortamında sorunları teknolojik olarak çözebilen bireyler olmaktan geçmektedir.

Öğrencilerin bu becerileri kazanması için kullanılacak en iyi yöntemlerden birinin bilgisayar kodlamanın ya da programlamanın öğretilmesi olduğunu gösteren araştırmalar ve uygulamalar olduğu bilinmektedir (Akpınar ve Altun, 2014). Bilgisayar eğitiminin hedef kitlesi ortaokul kademesinden başlamaktadır. Bu konuda gerekli niteliklerle donatılmış bireylerin bilgisayara yönelik tutumlarının artması ve teknolojiyi anlama sorunlarının ortadan kalkması beklenmektedir.

Bilişim Teknoloji ve Yazılım dersinin önemi, yakın zamanda ortaya çıkan blok kodlama 
yazılımları ve alternatif birçok öğrenme ortamlarının çıkması ile dikkat çekici olmuştur. Önceden mühendislik fakültelerinde kodlama eğitiminin temel bilgileri öğrenilirken, günümüzde ortaokullarda bu tarz uygulamalar ile daha erken ve temeli sağlam yazılım eğitimlerinin verilmesi kolaylaşmaktadır. Erken yaşta bilişim, kodlama gibi becerilerin gelişmesini sağlamak, öğrencilerin bilgisayara yönelik tutumu ve bu alandaki öğrenme çabası ile doğru orantılıdır.

\section{KURAMSAL ÇERÇEVE VE İLGILII ARAŞTIRMALAR}

Kodlama, bilgisayara verilen bir görevi nasıl gerçekleştireceğini söyleyen yönergeleri oluşturma süreci ya da oluşan sorunları çözmesi ve insan bilgisayar etkileşimini sağlaması için çeşitli adımların geliştirilip uygulandığı süreçtir (Pakman, 2018). Yazılım eğitimi, geçmiş yıllarda özel kurs ya da lisans eğitimleri alarak öğrenilmekteydi. Günümüzde tablet, telefon, gibi iletişim teknolojilerin akıllı cihaza dönüşmesi ve yaygın olarak kullanılması birçok alanda gelişmelere neden olmuştur. Özellikle eğitim müfredatlarının yenilenmesi, daha fazla bilgiye ulaşmak, pratik bilgiler edinme, öğrencilere dersi sevdirmek gibi amaçlar için yeni içerikler geliştirilmeye başlanmıştır. Bu gelişim özellikle bilişim derslerinin erken yaşta öğrenilmesi gerekliliği kanıtlar niteliktedir. Akpınar ve Altun (2014) çalışmalarında kodlama öğretiminin analitik düşünme, problem çözme ve grup çalışması gibi becerilerin gelişimini desteklediğini belirtilmişlerdir.

Bilgi teknolojilerindeki hızlı gelişmeler ve teknolojinin gelișmesi ile bireyler farkında olmasa bile teknoloji ile iç içe gelmiştir. Bu durum günlük hayatta yapabileceğimiz uzun bir banka işleminin elektronik ortamda kısa sürede yapılabilmesi gibi olanaklar sunmaktadır. Ülkelerin bilime ve teknolojiye bakış açısı, sanayilerin gelişmesi ve üretim süreçleri gibi birçok endüstriyel sistemlerin geliştirilebilmesi için bireylerin bilişim ve teknolojiliye bakış açısını değiştirilmelidir. Bu yüzden Bilişim Teknolojileri ve Yazılım dersi çok önemlidir. Sadece tüketen değil üreten toplum olunması için özellikle teknolojik alanda tutumların olumlu yönde oluşturulması gerekir. Bu amaç ile ilk bilgisayar dersi 1998 yılında ilköğretim okullarında müfredata eklenmiştir (MEB, 2019).

Çağımızda bireylerin bilişim teknolojilerine gereksinim duyacağı ve kendi karşılaştıkları problemleri çözmeleri için gerekli eğitimler alması gerekliliği bilinmektedir. Bunun için Milli Eğitim Bakanlığı, FATİH Projesi kapsamında 2015 yılında Eğitim Teknolojileri Zirvesi Paneli sonrasında ilgili bakanlık talimatları ile kodlama robotik dersi için müfredat hazırlatılmıştır. Kodlama robotik gibi etkinlikleri de içeren bu dersin 5, 6, 7 ve 8. sınıflarda okutulması için çalışmalar devam etmektedir (MEB, 2019).

Yapılan bir çalışmada kodlama platformları incelenmiştir. Erken yaşta kodlama eğitimi için kodlama ortamları karşılaștırılmıştır. 40'dan fazla programlama mantığını içeren platformların incelendiği araştırmada Code.org, Scratch gibi blok tabanlı yazılımların daha kullanışlı ve yapısı itibarı ile algoritma yapısının öğretilmesi için faydalı bulunmuştur (Baz, 2018).

Tekerek, Altan ve Akdağ (2012), algoritma ve akış diyagramları konusunun öğretiminde Scratch ortamının etkisini araștırmışlardır. Çalışma grubu 6. sınıfta 30 öğrenci deney grubu, 30 öğrenci kontrol grubu olmak üzere toplam 60 kişiden oluşmaktadır. Deney grubunda ders etkinlikleri Scratch kullanılarak oyun tabanlı öğrenme gerçekleştirilmiştir. Kontrol grubunda ise düz anlatım yöntemi tercih edilmiştir. Çalışma sonucunda algoritma öğretiminde Scratch kullanımının öğrencilerin öğrenmelerinde anlamlı farklılığa etkisi olmadığı belirlenmiştir.

Kert ve Uğraş (2009), tarafından yapılan araștırmada basit ve kullanımı kolay bir yazılım olan Scratch ortamının kodlama eğitimindeki görevini açıklamıştır. Bu araştırma Scratch yazılımın yanında öğrenme ve öğretme süreçleri tartışılmış ve öneriler verilmiştir. Erken yaşta kodlama öğretimin öğrencilerin düşünme becerilerine olumlu etkisi olduğunu ve akranları ile olan işbirlikli öğrenme, bilgiyi keşfetme gibi katkılarının olacağı belirtilmiştir. Çalışmada özellikle verilen kodlama eğitiminin öğrencilerin seviyesinde olması ve ortamın eğlenceli biçime dönüştürülmesi gerektiği vurgulamıştır.

Şahin ve Namlı (2017) tarafından yapılan araştırmada ilk kez algoritma eğitimi almış olan ortaokul öğrencilerinin BDE (Bilgisayar Destekli Eğitim) ve drama yöntemleriyle verilen algoritma 
eğitimi sonrası problem çözme becerileri incelenmiş ve her iki yöntemde de eğitim sonucunda problem çözme becerilerinde olumlu yönde anlamlı farklılık bulunmuştur.

Oluk ve diğerleri (2018) tarafından yapılan araştırmada Scratch kullanılarak deney grubuna verilen algoritma eğitimi sonucunda öğrencilerin algoritma geliştirme ve bilgi işlemsel düşünme becerilerinin, mevcut öğretim programı kullanılarak kontrol grubuna verilen algoritma eğitimi sonuçlarına göre anlamlı derecede daha fazla yükseldiği görülmüştür.

Kasalak (2017) tarafından yapılan araştırmada ortaokul düzeyindeki öğrencilerin kodlama robotik etkinlikleri ile öğrencilerin blok temelli programlamaya ilişkin öz-yeterlik algıları arasında anlamlı bir ilişki olup almadığını tespit edilmesi amaçlanmıştır. Ayrıca araştırmada kodlama etkinliklerine ilişkin öğrenci yaşantıları araştırılmış, kodlama robotik etkinliklerinin düzenlenmesi sürecinde dikkat edilmesi gereken bulgulara da yer verilmiştir. Araştırmada geliştirilen ölçek, 5 haftalık kodlama robotik etkinlikleri yapıldıktan sonra bir devlet okulunda 58 öğrenciye uygulanmıştır. Sonuç olarak öğrencilerin ön test son test sonuçlarına göre hem basit hem de karmaşık blok temelli programlamaya ilişkin öz-yeterlik algısı puanlarında grup içi pozitif yönde anlamlı değişimin meydana geldiği görülmüştür.

Numanoğlu ve Keser (2017) tarafından mBot ve Makeblock araçlarının kodlama ve robotik dersinde kullanılabilirliği ile ilgili yapılan çalışmada soyut kavramların daha kolay anlașılabileceği ve karmaşık kod yapısını somutlaştıran örnekleri incelenmiş ve kodlama robotik etkinliklerinde mBot gibi eğitim setlerinin kullanılabileceği belirtilmiștir.

Yüksel (2010), tarafından yapılan araştırmada 260 ortaokul öğrencisinin bilgisayara olan tutumları ile öğrenme stilleri arasındaki ilişki incelenmiştir. Bilgisayar tutumlarının cinsiyet değişkenine göre anlamlı bir fark göstermediği fakat kendine güven alt ölçeği sonucunda erkeklerin daha olumlu bir tutuma sahip olduğu belirtilmiştir. Bilgisayara ulaşılabilirlik açısından evde bilgisayarı olan öğrencilerin bilgisayarı olmayanlara göre daha olumlu tutuma sahip olduğu görülmüştür.

Sever (2014) tarafından yapılan araştırmada, Wang, Bergin ve Bergin (2014) tarafından geliştirilmiş olan derse katılım envanterinin Türk Kültürüne uyarlanması için çalışılmıştır. Türkçe formu ile İngilizce formunun tutarlılığının ve dilsel eşdeğerliğine yönelik ilişki değerlerinin 0.969 ve $0.699(\mathrm{p}<.05)$ arasında değiștiği belirlenerek araștırmanın geçerli olduğu görülmüştür. Bu envanter, Ankara'da 9, 10 ve 11. sınıflara devam eden 300 lise öğrencisine uygulanarak derse katılım envanterinin Türkçe uyarlanmış şekli hazırlanmıştır. Bu envanter, duyuşsal katılım, davranışsal katılım (uyma-itaat), davranışsal katılım (sınıf katılımı), bilişsel katılım, derse katılım gibi 5 alt boyuttan oluşmaktadır. Bu araştırmada da derse katılım envanterinin duyuşsal katılım alt boyutunda yer alan 6 madde kullanılmıştır.

Fidan (2018), tarafından "Scratch ile Programlama Öğretiminde Oyunlaştırmanın Öğrenci Katılımına Etkisi" konulu çalışma yapılmıştır. Toplam 37 öğrenciden oluşan örneklem grubuna Eğitimde Görsel ve Canlandırma dersinin Scratch programı ile oyunlaştırması yapılmıştır. Elde edilen bulgular sonucunda, Scratch programı ile oyunlaştırma uygulamasının derse katılımı ve derse karışı motivasyonları arttırdığı sonucuna ulaşılmıştır.

Yıldırım (2018), tarafından yapılan araştırmada Mobil Artırılmış Gerçeklik (MAG) uygulaması kullanılarak gerçekleştirilen fen öğretiminin, ortaokul öğrencilerinin fen ve teknolojiye yönelik tutumlarına ve akademik başarılarına etkisi araştırılmıştır. Çalışma Elâzığ İlinde 6. sınıfta öğrenim gören 76'sı kız, 67'si erkek toplam 143 öğrenciye yapılmıştır. Sonuçlar incelendiğinde, deney gruplarındaki öğrencilerin, dersin sürecinde mevcut ders kitabına bağlı kalan kontrol gruplarındaki öğrencilere göre akademik başarı düzeylerinde etkili olduğu, ancak fen ve teknolojiye yönelik tutum düzeylerinde etkili olmadığı görülmüştür. Öğrenciler derste kullanılan Mobil Artırılmış Gerçeklik (MAG) uygulamasının kullanımının soyut kavramları somutlaştırma, öğrenmeyi basitleştirme gibi 
üstünlükleri olduğunu belirtmişlerdir.

\section{ARAŞTIRMANIN AMACI, YÖNTEMİ VE KAPSAMI}

Yapılan bu araştırmanın amacı, kodlama robotik etkinliklerinin ortaokul öğrencilerinin bilgisayara yönelik tutumuna ve Bilişim Teknolojileri ve Yazılım dersine duyuşsal katılımına etkisini belirlemektir. Bu çalışma 2018-2019 eğitim öğretim yılı Konya ilinde özel bir okulda bulunan 68 öğrenci ile sınırlıdır. Araştırmada yarı deneysel desen ön test - son test kontrol gruplu araştırma modeli kullanılmıştır. Deney ve kontrol gruplarına deney öncesi ve deney sonrası ölçekler yapılmıştır. $\mathrm{Bu}$ araştırmada ADDIE öğretim tasarımı modeliyle deney grubu öğrencilerine kodlama etkinliklerinin yer aldığı öğretim tasarımı, kontrol grubu öğrencilerine ofis programlarının öğretiminin yer aldığı öğretim tasarımı geliștirilmiștir (Șekil 1).

Şekil 1. Kodlama Etkinliklerine İlişkin Öğretim Tasarım Süreci

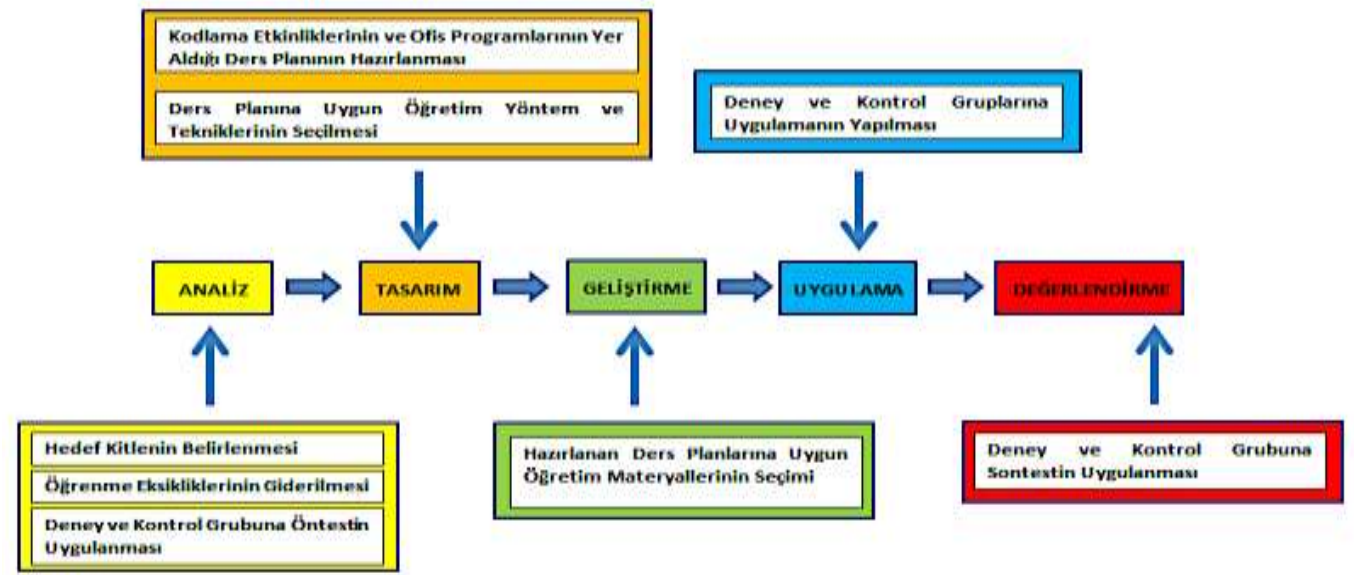

Araştırmada öğrencilerin bilgisayara yönelik tutumlarını ölçmek için Demir ve Yurdugül tarafından 2004 yılında geliştirilen "Ortaokul ve Lise Öğrencileri için Bilgisayara Yönelik Tutum Ölçeği” ve Wang, Bergin ve Bergin (2014) tarafından geliștirilmiș "Derse Katılım Envanterinin Sever tarafından 2014 yılında Türk kültürüne uyarlanmıș hali olan "Derse Katılım Envanteri” uygulanmıştır. Deney ve kontrol gruplarına deney öncesi ve sonrası ölçümler yapılmıştır. Araştırma da kullanılan modelin șematik gösterimi Tablo 1' de verilmiștir.

Tablo 1. Çalışmada Kullanılan Araştırma Modeline Göre Uygulama Süreci

\begin{tabular}{cccc}
\hline \multirow{2}{*}{ Grup } & $\begin{array}{c}\text { Uygulama Öncesi } \\
\text { (Ön Test) }\end{array}$ & Uygulama Süreci & $\begin{array}{c}\text { Uygulama Sonrası } \\
\text { (Son Test) }\end{array}$ \\
\hline \multirow{2}{*}{ Deney Grubu } & DKE-1 & Kodlama Robotik & DKE-2 \\
& TÖ-1 & Etkinlikleri & DKE-2 \\
\hline \multirow{2}{*}{ Kontrol Grubu } & DKE-1 & Ofis Programlari & TÖ-2 \\
\hline
\end{tabular}

Deney grubuna kodlama ve robotik konuları ile desteklenmiș bilișim teknoloji ve yazılım dersi öğretim programı, kontrol grubuna ise bilişim teknoloji ve yazılım dersi içerisinde yer alan ofis programlarını içerek program ile ders anlatılmıştır.

\section{KATILIMCILARIN DEMOGRAFIK ÖZELLÍKLERİ}

Araştırmanın çalışma grubunu 26'sı kız, 42'si erkek olmak üzere toplam 68 beşinci ve altıncı sınıf öğrencisi oluşturmaktadır. Çalışma grubunun cinsiyet açısından dağılımlarına ilişkin veriler Tablo 2'de yer almaktadı. 
Tablo 2. Örneklem Grubunun Özellikleri

\begin{tabular}{cccc}
\hline & Değişkenler & Frekans (F) & Yüzde (\%) \\
\hline \multirow{2}{*}{ Cinsiyet } & Kiz & 26 & 38,2 \\
\cline { 2 - 4 } & Erkek & 42 & 61,8 \\
\hline
\end{tabular}

Uygulama sürecinde dersler, kontrol grubunda bilişim teknolojileri ve yazılım dersi öğretim programına göre, deney grubunda ise kodlama ve robotik konuları ile desteklenen bilişim teknolojileri ve yazılım dersi öğretim programına uygun olarak işlenmiştir. Deneysel uygulama öncesinde ve sonrasında derse katılım envanteri, bilgisayara yönelik tutum ölçeği ön test ve son test olarak uygulanmış olup çalışma sonucunda kodlama robotik etkinlikleri ile desteklenmiş bilişim teknolojileri ve yazılım dersinin, bilgisayar dersine katılım ve bilgisayara yönelik tutum üzerinde etkili olup olmadığı, uygun istatistiksel yöntemlerle analiz edilmiştir.

\section{BULGULAR}

$\mathrm{Bu}$ araştırmada, uygulama öncesinde deney ve kontrol gruplarının arasında farklılığın olup olmadığını belirlenmek için aşağıdaki analizler yapılmıştır.

\section{Uygulama Öncesi Deney ve Kontrol Gruplarının Öntest Puanlarının Karşılaştırılması}

Kodlama robotik etkinliklerinin kullanıldığı deney gruplarının derse katılım envanteri öntest puanları ile ofis programlarının gösterildiği kontrol grubunun derse katılım envanteri öntest puanları arasında farklılığın olup olmadığını belirlemek için bağımsız örneklem t-testi yapılmıştır.

Tablo 3. Derse Katılım Envanterine Göre Grupların Öntest Sonuçları

\begin{tabular}{lcccccc}
\hline & $\mathrm{N}$ & $\mathrm{X}$ & $\mathrm{Ss}$ & $\mathrm{Sd}$ & $\mathrm{t}$ & $\mathrm{p}$ \\
\hline Kontrol Grubu & 33 & 3.36 & 1.24 & \multirow{2}{*}{66} & \multirow{2}{*}{.90} & \multirow{2}{*}{.37} \\
\hline Deney Grubu & 35 & 3.12 & 1.14 & & & \\
\hline
\end{tabular}

Deney ve kontrol grupları arasında yapılan derse katılım envanteri ön test sonucu kontrol grubunun ön test puanının ortalaması 3.36, standart sapması 1.24, deney grubunun ön test puanının ortalaması 3.12, standart sapması 1.14 olarak bulunmuştur. Yapılan bağımsız örneklem t-testi sonucu deney ve kontrol gruplarının derse katılım envanteri puanlarının istatistiksel açıdan anlamlı bir farklıllk göstermediği söylenebilir ( $\mathrm{t}=0.90, \mathrm{p}>.05)$.

Bilgisayara Yönelik Tutum Ölçeği (BYTÖ), 3 alt boyuttan oluşmaktadır. Bu alt boyutlar; bilgisayardan hoşlanma, bilgisayar kaygısı ve bilgisayarın önemidir. Bu analizde kodlama robotik etkinliklerinin kullanıldığı deney gruplarının BYTÖ alt boyutlarından olan bilgisayardan hoşlanma öntest puanları ile ofis programlarının gösterildiği kontrol grubunun BYTÖ alt boyutlarından olan bilgisayardan hoşlanma öntest puanları arasında farklılığın olup olmadığını belirlemek için bağımsız örneklem t-testi yapılmıştır.

Tablo 4. Bilgisayara Yönelik Tutum Ölçeğine Göre Gruplarının Öntest Sonuçları

\begin{tabular}{|c|c|c|c|c|c|c|c|}
\hline & & $\mathrm{N}$ & $\overline{\mathrm{X}}$ & Ss & Sd & $\mathrm{t}$ & $\mathrm{p}$ \\
\hline \multirow{2}{*}{$\begin{array}{c}\text { Bilgisayardan } \\
\text { Hoşlanma }\end{array}$} & Kontrol Grubu & 33 & 3.42 & .93 & \multirow{2}{*}{66} & \multirow{2}{*}{.74} & \multirow{2}{*}{.46} \\
\hline & Deney Grubu & 35 & 3.60 & .87 & & & \\
\hline \multirow{2}{*}{$\begin{array}{l}\text { Bilgisayarın } \\
\text { Önemi }\end{array}$} & Kontrol Grubu & 33 & 3.22 & 1.28 & \multirow{2}{*}{66} & \multirow{2}{*}{.36} & \multirow{2}{*}{.72} \\
\hline & Deney Grubu & 35 & 3.31 & .95 & & & \\
\hline Bilgisayar & Kontrol Grubu & 33 & 3.62 & 1.11 & \multirow{2}{*}{66} & \multirow{2}{*}{1.23} & \multirow{2}{*}{.22} \\
\hline Kaygısı & Deney Grubu & 35 & 3.91 & .77 & & & \\
\hline
\end{tabular}

Deney ve kontrol grupları arasında yapılan bilgisayara yönelik tutum ölçeği sırası ile tablo 4'te verilmiştir. Bilgisayardan hoşlanma alt boyutu öntest sonucu kontrol grubunun öntest puanının ortalaması 3.42, standart sapması .93, deney grubunun öntest puanının ortalaması 3.60, standart sapması .87, bilgisayar kaygısı alt boyutu ön test sonucu kontrol grubunun öntest puanının ortalaması 
3.62, standart sapması 1.11, deney grubunun öntest puanının ortalaması 3.91, standart sapması .77 ve bilgisayarın önemi alt boyutu ön test sonucu kontrol grubunun ön test puanının ortalaması 3.22, standart sapması 1.28, deney grubunun ön test puanının ortalaması 3.31, standart sapması .95 olarak bulunmuştur.

Yapılan bağımsız örneklem t-testi sonucu deney ve kontrol gruplarının bilgisayara yönelik tutum ölçeği, bilgisayardan hoşlanma, bilgisayarın önemi ve bilgisayar kaygısı puanlarının istatistiksel açıdan anlamlı bir farklılık göstermediği söylenebilir ( $p>.05)$.

\section{Deney Grubunun Öntest ve Sontest Puanlarına İlişkin Bulgular}

$\mathrm{Bu}$ bölümde deney grubunun öntest ve sontest puanlarına ilişkin bulgulara yer verilmiştir. Yapılan öntest ve sontest sonuçları arasında farklılığın olup olmadığını belirlemek için bağımlı örneklem t-testi yapılmıştır.

Tablo 5. Deney Grubu Derse Katılım Envanteri ve BYTÖ Öntest ve Sontest Sonuçları

\begin{tabular}{|c|c|c|c|c|c|c|c|}
\hline & & $\mathrm{N}$ & $\overline{\mathrm{X}}$ & Ss & $\mathrm{Sd}$ & $\mathrm{t}$ & $\mathrm{p}$ \\
\hline \multirow{2}{*}{$\begin{array}{c}\text { Derse Katılım } \\
\text { Envanteri* }\end{array}$} & Deney Grubu Öntest & 35 & 3.12 & 1.14 & \multirow{2}{*}{34} & \multirow{2}{*}{.21} & \multirow{2}{*}{.83} \\
\hline & Deney Grubu Sontest & 35 & 3.06 & 1.16 & & & \\
\hline \multicolumn{8}{|c|}{ Bilgisayara Yönelik Tutum Ölçeği* } \\
\hline Bilgisayardan & Deney Grubu Öntest & 35 & 3.60 & .87 & \multirow{2}{*}{34} & \multirow{2}{*}{.40} & \multirow{2}{*}{.68} \\
\hline Hoșlanma & Deney Grubu Sontest & 35 & 3.51 & .77 & & & \\
\hline \multirow{2}{*}{$\begin{array}{l}\text { Bilgisayarın } \\
\text { Önemi }\end{array}$} & Deney Grubu Öntest & 35 & 3.30 & .95 & \multirow{2}{*}{34} & \multirow{2}{*}{.12} & \multirow{2}{*}{.90} \\
\hline & Deney Grubu Sontest & 35 & 3.35 & .93 & & & \\
\hline Bilgisayar & Deney Grubu Öntest & 35 & 3.91 & .78 & \multirow[b]{2}{*}{34} & \multirow{2}{*}{1.27} & \multirow[b]{2}{*}{.21} \\
\hline Kaygisı & Deney Grubu Sontest & 35 & 3.65 & .79 & & & \\
\hline
\end{tabular}

Deney grupları arasında yapılan derse katılım envanteri ön test ve son test sonuçları sırasıyla ön test puanının ortalaması 3.12, standart sapması 1.14, son test puanının ortalaması 3.06, standart sapması 1.16, bilgisayar yönelik tutum ölçeği bilgisayardan hoşlanma alt boyutu ön test ve son test sonuçları, sırasıyla ön test puanının ortalaması 3.60, standart sapması .87, son test puanının ortalaması 3.51, standart sapması .77, bilgisayarın önemi alt boyutuna göre ön test ve son test sonuçları, sırasıyla ön test puanının ortalaması 33, standart sapması .95 son test puanının ortalaması 3.35, standart sapması .93, bilgisayar kaygısı alt boyutuna göre ön test ve son test puanlarının sonuçları, sırasıyla ön test puanının ortalaması 3.91, standart sapması .78, son test puanının ortalaması 3.65, standart sapması .79 olarak bulunmuştur.

Yapılan bağımlı örneklem t-testi sonucu deney gruplarının ön test ve son test puanlarına göre derse katılım envanteri için ve bilgisayara yönelik tutum ölçeğinin alt boyutları sırası ile tablo 5'de verilmiştir. Buna göre her iki ölçek puanlarının arasında istatistiksel açıdan anlamlı bir farklılık görülmemiştir ( $\mathrm{p}>$.05).

\section{Kontrol Grubunun Öntest ve Sontest Puanlarına İlişkin Bulgular}

$\mathrm{Bu}$ bölümde kontrol grubunun öntest ve sontest puanlarına ilişkin bulgulara yer verilmiștir. Yapılan öntest ve sontest sonuçları arasında farklılığın olup olmadığını belirlemek için bağımlı örneklem t-testi yapılmıştır.

Tablo 6. Kontrol Grubu Derse Katılım Envanteri ve BYTÖ Öntest ve Sontest Sonuçları

\begin{tabular}{|c|c|c|c|c|c|c|c|}
\hline & & $\mathrm{N}$ & $\mathrm{X}$ & Ss & $\mathrm{Sd}$ & $\mathrm{t}$ & $\mathrm{p}$ \\
\hline \multirow{2}{*}{$\begin{array}{c}\text { Derse Katılım } \\
\text { Envanteri* }\end{array}$} & Kontrol grubu ön test & 33 & 3.38 & 1.23 & \multirow[b]{2}{*}{32} & \multirow[b]{2}{*}{2.78} & \multirow{2}{*}{.00} \\
\hline & Kontrol grubu son test & 33 & 2.50 & .92 & & & \\
\hline \multicolumn{8}{|c|}{ Bilgisayara Yönelik Tutum Ölçeği* } \\
\hline \multirow{2}{*}{$\begin{array}{c}\text { Bilgisayardan } \\
\text { Hoşlanma }\end{array}$} & Kontrol Grubu Öntest & 33 & 3.43 & .93 & \multirow{2}{*}{32} & \multirow{2}{*}{.79} & \multirow{2}{*}{.43} \\
\hline & Kontrol Grubu Sontest & 33 & 3.28 & .80 & & & \\
\hline \multirow{2}{*}{$\begin{array}{l}\text { Bilgisayarın } \\
\text { Önemi }\end{array}$} & Kontrol Grubu Öntest & 33 & 3.22 & 1.28 & \multirow{2}{*}{32} & \multirow{2}{*}{-.18} & \multirow{2}{*}{.85} \\
\hline & Kontrol Grubu Sontest & 33 & 3.26 & .75 & & & \\
\hline
\end{tabular}




\begin{tabular}{|c|c|c|c|c|c|c|c|}
\hline Bilgisayar & Kontrol Grubu Öntest & 33 & 3.62 & 1.11 & 34 & 1.12 & .27 \\
\hline Kaygisı & Kontrol Grubu Sontest & 33 & 3.36 & .88 & 34 & 1.12 & .21 \\
\hline
\end{tabular}

Kontrol grupları arasında yapılan derse katılım envanteri ön test ve son test puanlarının sonuçları sırasıyla ön test puanının ortalaması 3.38, standart sapması 1.23 , son test puanının ortalaması 2.50, standart sapması. .92, bilgisayar yönelik tutum ölçeği, bilgisayardan hoşlanma alt boyutu öntest ve sontest sonuçları, sırasıyla ön test puanının ortalaması 3.43, standart sapması .93, son test puanının ortalaması 3.28, standart sapması .80, bilgisayarın önemi alt boyutu ön test ve son test sonuçları, sırasıyla ön test puanının ortalaması 3.22, standart sapması .1.28, son test puanının ortalaması 3.26, standart sapması .75, bilgisayar kaygısı alt boyutu ön test ve son test sonuçları, sırasıyla öntest puanının ortalaması 3.62, standart sapması 1.11, sontest puanının ortalaması 3.36, standart sapmasi .88 olarak bulunmuştur.

Yapılan bağımlı örneklem t-testi sonucu kontrol grubunun bilişim dersine katılım envanteri ve bilgisayara yönelik tutum ölçeğinin alt boyutları sırası ile Tablo 6'da verilmiştir. Buna göre kontrol grubunun BDKE öntest ve sontest puan ortalamaları arasındaki fark incelendiğinde, sontest puan ortalamasında azalma olduğu ve bu azalma istatistiksel olarak anlamlı bulunmuştur $(\mathrm{p}<0.05)$. Bilgisayara yönelik tutum ölçeği öntest ve sontest puan ortalamaları arasındaki fark incelendiğinde, istatistiksel olarak anlamlı bir fark görülmemiştir.

\section{Uygulama Sonrası Kontrol ve Deney Gruplarının Sontest Puanlarına İlişkin Bulgular}

Kodlama robotik etkinlikleri ile ders işlenen deney grubu ile ofis programlarının eğitimi verilen kontrol gruplarının BDKE ve BYTÖ sontest puanları arasında farklılığın olup olmadığını belirlemek için bağımlı örneklem t-testi yapılmıştır.

Tablo 7. Kontrol ve Deney Gruplarının BDKE ve BYTÖ Sontest Sonuçları

\begin{tabular}{|c|c|c|c|c|c|c|c|}
\hline & & $\mathrm{N}$ & $\overline{\mathrm{X}}$ & Ss & $\mathrm{Sd}$ & $\mathrm{t}$ & $\mathrm{p}$ \\
\hline \multirow[t]{2}{*}{ Derse Katılım } & Kontrol grubu sontest & 33 & 2.50 & .91 & \multirow{2}{*}{66} & \multirow{2}{*}{2.18} & \multirow{2}{*}{.03} \\
\hline & Deney grubu sontest & 35 & 3.06 & 1.16 & & & \\
\hline \multicolumn{8}{|c|}{ Bilgisayara Yönelik Tutum Ölçeği* } \\
\hline \multirow{2}{*}{$\begin{array}{c}\text { Bilgisayardan } \\
\text { Hoșlanma }\end{array}$} & Kontrol Grubu Öntest & 33 & 3.29 & .80 & \multirow{2}{*}{66} & \multirow{2}{*}{2.18} & \multirow{2}{*}{.23} \\
\hline & Deney Grubu Sontest & 35 & 3.50 & .77 & & & \\
\hline \multirow{2}{*}{$\begin{array}{l}\text { Bilgisayarın } \\
\text { Önemi }\end{array}$} & Kontrol Grubu Öntest & 33 & 3.26 & .75 & \multirow{2}{*}{66} & \multirow{2}{*}{.41} & \multirow{2}{*}{68} \\
\hline & Deney Grubu Sontest & 35 & 3.34 & .93 & & & \\
\hline \multirow{2}{*}{$\begin{array}{c}\text { Bilgisayar } \\
\text { Kaygisı }\end{array}$} & Kontrol Grubu Öntest & 33 & 3.36 & .89 & \multirow{2}{*}{66} & \multirow{2}{*}{1.46} & \multirow{2}{*}{.14} \\
\hline & Deney Grubu Sontest & 35 & 3.66 & .79 & & & \\
\hline
\end{tabular}

Kontrol grubu bilişim dersine duyuşsalkatılım envanteri sontest puan ortalaması 2.50 , standart sapması .91, deney grubu bilişim dersine katılım envanteri sontest puan ortalaması 3.05 ve standart sapması 1.16'dır.Gruplar arasında fark olup olmadığını belirlemek için bağımsız örneklem t testi yapılmıștır ( $\mathrm{t}=2.18 ; \mathrm{p}<.05)$. Yani kodlama ve robotik etkinliklerinin kullanıldığı deney grubunun derse duyuşsal katılım düzeylerinin kontrol grubunda yer alan öğrencilerden daha yüksek olduğu söylenebilir.

Deney ve kontrol grupları için Bilgisayara yönelik tutum ölçeğinin alt boyutlarından aldıkları puanların karşılaştırılması için bağımsız örneklem t testi yapılmıştır. Yapılan analiz sonucu gruplar arasında bilgisayara yönelik tutum açısından istatistiksel bakımdan anlamlı bir farklılık oluşmadığı belirlenmiştir ( $\mathrm{p}>.05)$.

\section{SONUÇ VE ÖNERILLER}

Bu çalışma Konya'da özel bir okulda öğrenim gören ortaokul 5. sınıf ve 6. sınıf öğrencilerinin bilişim teknolojileri ve yazılım dersi içerisinde kodlama etkinlikleri kullanılarak tasarlanan ders planının öğrencilerin "Bilgisayara Yönelik Tutum” ve "Bilişim Dersine Duyuşsal Katılımlarına Etkisi” 
araştırılmıştır. Araştırma kapsamında 26 kız, 42 erkek olmak üzere 68 öğrenciye ulaşılmış ve veriler ölçek yoluyla toplanmıştır. Çalışma grubunda yer alan öğrencilerin 35'ini deney grubu, 33'ünü kontrol grubu oluşturmaktadır. Öğrencilerin tamamının internet erişimine sahip oldukları belirlenmiştir.

Araştırmanın birinci alt amacı doğrultusunda, kodlama etkinlikleri gören ortaokul öğrencilerinin bilişim teknolojileri dersine duyuşsal katılımın düzeyi arasında anlamlı bir farklılık gösterip göstermediği araştırılmıştır. Kodlama etkinliklerinin yapıldığı deney grubu öğrencilerinin öntest ve sontest sonuçları karşılaştırıldığında öğrencilerin derse olan duyuşsal katılım puanlarını olumlu ya da olumsuz yönde etkilenmediği sonucuna ulaşılamamıştır. Bunun sebebi yapılan uygulamanın 8 hafta gibi bir sürede kısıtlı olması, haftalık 2 saat yapllan ders sürecinde öğretim planının zamanında bitirilmesi için uygun öğretim yöntem ve tekniklerinin yeterli kullanılmayışı, uygulama sırasında düzenli geribildirimin yapılmaması, uygulama ile ilgili yazılı kaynak verilmemesi gibi nedenlerden kaynaklanmış olabileceği gözlemlenmiştir. Bu nedenle deney grubu öğrencilerinin bilgisayara yönelik tutum ve bilişim dersine duyuşsal katılım düzeylerinin değişmediği görülmüştür. Elde edilen bu sonuçlar bazı çalışmalar ile benzerlik göstermektedir. Kasalak (2017) yapmış olduğu çalışmada öğrencilerin Scratch ile kodlama etkinlikleri sonrasında ilk haftalarda eğlendikleri ve ilgili oldukları fakat 4. hafta sonunda sıkıldıklarını belirtmiştir Tekerek, Altan ve Akdağ (2012), yapmış olduğu çalışmada algoritma öğretiminde Scratch kullanımının öğrencilerin öğrenmeleri üzerinde anlamlı farklılığa etkisi olmadığını açıklamıştır. Yapılan analiz sonuçları karşılaştırıldığında kodlama eğitimi alan öğrencilerin derse duyuşsal katılım düzeyinin ofis programlarına ait eğitimi alan öğrencilerden daha yüksek olduğu bulunmuştur. Bu araştırmada öğretim süreci incelendiğinde kullanılan öğretim materyallerin farklılığı öğrencilerin derse katılımlarını etkileyen bir neden olduğu düşünülmektedir. Kodlama etkinliği sırasında Arduino Uno, sensörler ve Scratch gibi araçların kullanımı, öğrencilerin bu alanda hayal güçlerini etkilediği, daha fazla etkinlik yapma isteklerini ortaya çıkardığı gözlemlenmiştir. Bu sonuç Şenol (2011) tarafından yapılan çalışma ile benzerlik göstermektedir. 0 çalışmada bilgisayar dersinde ders etkinlikleri arttırılarak öğrencilerin bilişim dersine katılımları yükseltilmiştir. Ayrıca birden fazla öğretim materyallerin kullanıldığı ve bunun sonucunda somut örneklerin bulunduğu etkinlikler deney grubunun bilişim dersine duyuşsal katılım düzeyini etkilemez iken kontrol grubunda bilişim dersine duyuşsal katılımın olumsuz etkilendiği görülmüştür. Bunun nedeni somut örneklerin kullanımının önemini ifade etmektedir. Numanoğlu ve Keser (2017), tarafından yapılan mBot robotik eğitim setinin kodlama robotik dersinde kullanımının incelendiği araştırmada, erken yaşta kodlama öğretiminde soyut kavramların daha basit öğrenilebileceği, Scratch gibi programlamalar ile yazılan kodların somut halini görebilmeyi sağlayan bu setlerin gerekliliğini belirtmişlerdir. Yapılan başka bir araştırmada öğrencilere verilen kodlama robotik ve arttırılmış gerçeklik gibi eğitimlerin yer aldığı uygulamaların soyut kavramları somutlaştırma, karmaşık kavramları örneklendirme gibi öğrenmeyi kolaylaştıran üstünlükleri olduğu görülmüştür (Yıldırım, 2018).

Araştırmanın ikinci alt amacı doğrultusunda, kodlama etkinlikleri gören ortaokul öğrencilerinin bilgisayara yönelik tutumlarında anlamlı bir farklılık gösterip göstermediği araştırılmıștır. Bu araștırmada deney grubuna yapılan analiz sonucunda bilgisayara yönelik tutum ölçeği, bilgisayardan hoşlanma alt boyutu, bilgisayarın önemi alt boyutu ve bilgisayar kaygısı alt boyutu öntest ve sontest puanları arasında anlamlı bir farklılık olmadığı görülmüştür. Küçük ve Şişman (2016), tarafından yapılan araştırmada da öğretmenlerin kodlama dersindeki deneyimleri incelenmiş ve öğrencilerin robotlarla olan etkileşiminin öğrencilerin motivasyonunu arttırdığı ancak derse olan tutumlarında etkisi olmadığı bulunmuştur.

Sonuçlar incelendiğinde, görsel ve somut örnekleri daha çok kullanan deney grubu öğrencilerinin derse katılım oranının daha yüksek olduğu gözlemlenmiştir. Bunun en önemli nedenlerinden birisi somut örneklerin çok kullanıldığı ders işlenme sürecidir. Yapılan başka bir araştırmada da henüz somut işlem dönemindeki ortaokul 5. sinıf öğrencilerinin Scratch ile programlama etkinliklerine yönelik ilgi ve etkinliklerini gerçekleștirmeye ilişkin derse katılım ve isteklilik düzeylerinin yüksek olduğu tespit edilmiştir (Kasalak, 2017). 
Bu araștırmada kontrol grubu öğrencilerinin bilgisayara yönelik tutumları değișmezken bilișim dersine duyuşsal katılımlarının azalmış olduğu, deney grubunda yer alan öğrencilerin ise bilgisayara yönelik tutum ve bilişim dersine duyuşsal katılımlarının etkilenmediği bulunmuştur. Genel olarak her iki grupta da bilgisayara yönelik tutumların değișmediği bilinirken bilişim dersine duyuşsal katılımı etkileyen deney grubunda yapılan uygulamalar sonucu ortaya çıkmıştır. Kontrol grubun öğrencilerinin uygulama öncesinde bilişim dersine duyuşsal katılım düzeyleri yüksek iken Bilişim Teknolojileri ve Yazılım dersi içerisinde ofis programları eğitimi sonrasında bilişim dersine duyuşsal katılım düzeyi düşmüştür. Deney grubu öğrencilerinin uygulama öncesi ve uygulama sonrası bilişim dersine duyuşsal katılımının olumsuz yönde etkilenmemesi ve derse katılımlarının değişmemesinin sebebi Arduino, Tinkercad gibi etkinlikler ile eğitimin somut olarak işlenmesinden kaynaklanmış olduğu söylenebilir.

\section{KAYNAKÇA}

Akpınar, Y. ve Altun, Y. (2014). Bilgi Toplumu Okullarında Programlama Eğitimi Gereksinimi. İlköğretim Online, 13(1), 1- 4.

Baz, F. Ç. (2018). Çocuklar İçin Kodlama Yazılımları Üzerine Karşılaştırmalı Bir İnceleme. Curr Res Educ, 4(1), 12-56.

Demir, Ö \& Yurdugül, H (2014). Ortaokul ve Lise Öğrencileri için Bilgisayara Yönelik Tutum Ölçeğinin Türkçe'ye Uyarlanması. Türk Eğitim Derneği, Eğitim ve Bilim, 39 (2014), 176 247-256.

Fidan, A., (2016). Scratch ile Programlama Öğretiminde Oyunlaştırmanın Öğrenci Katılımına Etkisi, Yüksek Lisans Tezi, Uludağ Üniversitesi, Bursa.

Gagne, R. M. ve Briggs, L. J. (1974). Principles of Instructional Design. NewYork: Holt, Rinehart and Winston.

Gagne, R. M. (1985). The Conditions of Learning and Theory of Instruction (Dördüncü Baskı). NewYork: Holt, Rinehart ve Winston.

Karakaş, M. M. (2015). Ortaokul Sekizinci Sınıf Öğrencilerinin Fen Bilimlerine Yönelik 21.Yüzyıl Beceri Düzeylerinin Ölçülmesi. (Yayınlanmamış Yüksek Lisans Tezi), Eskişehir Osmangazi Üniversitesi Eğitim Bilimleri Enstitüsü, Eskişehir.

Kasalak, İbrahim. "Robotik Kodlama Etkinliklerinin Ortaokul Öğrencilerinin Kodlamaya İlişkin Özyeterlik Algılarına Etkisi Ve Etkinliklere İlişkin Öğrenci Yaşantıları.” Yayınlanmış Yüksek Lisans Tezi. Ankara: Hacettepe Üniversitesi Ĕgitim Bilimler Enstitüsü, 2017.

Kert, S.B. ve Uğraș, T. (2009). Programlama eğitiminde sadelik ve eğlence: Scratch örneği. I. Uluslararası Eğitim Araştırmaları Kongresi, Çanakkale.

Küçük, S. ve Şişman, B. (2016). İlkokul öğrencileriyle gerçekleştirilen birebir robotik öğretiminde öğreticilerin deneyimleri. İlköğretim Online, 16(1). https://doi.org /10.17051/io.2017.12092.s.

MEB,.(2019). Bilişim Teknolojileri Ve Yazılım Dersi Programı, Talim Terbiye Kurulu Başkanlığı, Ankara, http://mufredat.meb.gov.tr/ProgramDetay.aspx?PID=374, 25 Nisan 2018.

MEB,.(2019)..https://yegitek.meb.gov.tr/www/haydi-cocuklar-kodlamaogrenmeye/icerik/1504, adresinden 10.04.2019 tarihinde erişilmiştir.

Numanoğlu M., Keser H., (2017), Programlama Öğretiminde Robot Kullanılan Mbot Örneği, Bartın Üniversitesi Eğitim Fakültesi Dergisi, Bartın, Türkiye, 497515. 
Oluk, A., Korkmaz, Ö. ve Oluk, A.H. (2018). Scratch'ın 5.Sınıf Öğrencilerinin Algoritma Geliştirme ve Bilgiİşlemsel Düşünme Becerilerine Etkisi. Turkish Journal of Computer and Mathematics Education, Vol.9.No.1.,54-71.

Pakman, Nabi. "8-10 Yaş Grubu Öğrencilere Uygulanan Temel Düzey Kodlama, Robotik, 3d Tasarım Ve Oyun Tasarımı Eğitiminin Problem Çözme Ve Yansıtıcı Düşünme Becerilerine Etkisi ." Yayınlanmış Yüksek Lisans Tezi. İstanbul: Bahçeşehir Üniversitesi Eğitim Bilimler Enstitüsü, 2018.

Scratch For Arduino, http://s4a.cat/ , adresinden 24.08.2018 tarihinde erişilmiştir.

Sayın, Z., ve Seferoğlu, S. S., (2016). “Yeni Bir 21. Yüzyıl Becerisi Olarak Kodlama Eğitimi ve Kodlamanın Eğitim Politikalarına Etkisi", 15 Mayıs 2019.

Scratch, (2018). https://Scratch.mit.edu/about, adresinden 30.01.2018 tarihinde erişilmiştir.

Seferoğlu, S.S. (2007). Öğretim Teknolojileri ve Materyal Geliştirme. Ankara: Pegem Yayıncllık.

Senemoğlu N. (2002). Gelişim Öğrenme ve Öğretim Kuramdan Uygulamaya, Gazi Kitabevi, Ankara.

Sever, M. (2014). Derse Katılım Envanterinin Türk Kültürüne Uyarlanması. Türk Eğitim Derneği, Eğitim ve Bilim, 39(2014), 176 171-182.

Şahin ve Namlı (2017), Algoritma Eğitiminin Problem Çözme Becerisi Üzerine Etkisi, Recep Tayyip Erdoğan Üniversitesi Sosyal Bilimler Dergisi, 135-153.

Şenol, Mine “ilköğretim Öğrencilerinin Bilgisayar Tutumlarının İncelenmesi Ve Bilgisayar Dersi İçin Öğrenme Stillerini Göz Önüne Alan Bir Metodolojinin Geliştirilmesi”. Yayınlanmış Yüksek Lisans Tezi. İstanbul: Bahçeșehir Üniversitesi Fen Bilimleri Enstitüsü, 2011.

Şimşek, A. (2013). Öğretim Tasarımı Ve Modelleri. Çağıltay, K. ve Göktaş, Y. (Ed.), Öğretim teknolojilerinin temelleri: Teoriler, araştırmalar, eğilimler içinde (99-116). Ankara: Pegem Akademi.

Tekerek, M., Altan, T., ve Akdağ, M. A. (2012). The effect of Scratch on student's achievement in teaching algorithm, Proceedings of 6th International Computer \&Instructional Technology Symposium, 5459, Gaziantep University, Gaziantep, Turkey, October 2012.

Yüksel, E. (2010). İlköğretim II. Kademe Öğrencilerinin Bilgisayar Tutumları Ve Öğrenme Stilleri Arasındaki İlişkinin Belirlenmesi, Yüksek Lisans Tezi İstanbul: Bahçeşehir Üniversitesi. 


\section{EXTENDED ABSTRACT}

\section{INTRODUCTION}

Nowadays, IT technologies are evolving taking. Following this development closely and developing technology is one of the skills we hear today. Computers, smart phones, virtual reality glasses, smart boards etc. devices have increased the necessary information to learn. Virtual and augmented technologies are developed, even cars are equipped with smart technologies. Being the only user of such technological innovations has become insufficient for us. New information has led to different problems. Our perspective on these problems is directly proportional to the attitude of the users towards the computer (Sever, 2014).

It is known that in order to change the attitude towards computer, it is necessary to acquire the skills appropriate to the target audience with an education. These skills indicate that the importance of computer in occupations is increasing. It is known that one of the best methods for students to acquire these skills is to teach computer coding or programming (Akpınar \& Altun, 2014). In order to understand the basic skills, it is thought to start from the first level in computer teaching as well as foreign language teaching. In this way, it is expected that the attitudes of individuals and society towards computers and understanding of technology problems will disappear in the future.

Information Technology and Software course has gained value with the emergence of block coding software and many alternative learning environments. While the basic knowledge of coding education was previously learned in engineering faculties, it is now easier to give earlier education in secondary education with such practices. It is directly proportional to students' attitudes towards computer and learning effort in this field in order to develop skills such as informatics and coding at an early age.

\section{METHOD}

\section{Research Model}

In the research, a quasi - experimental design pre - test and post - test control group research model was used. Measurement tools were applied to the groups before and after the experiment. In this research, instructional design including coding activities for experimental group students and instructional design with office programs for control group students were developed with ADDIE instructional design model.

\section{Participants}

The study group of the research consists of a total of 68 students, 35 of whom are experimental group and 33 of which are control group who are attending 5th and 6th grade in a private secondary school in Konya in 2018 - 2019 academic year.

\section{Data Collection Tools}

"Personal Information Form", "Classroom Engagement Inventory" and "Scale of Students' Attitudes towards Computer" were used as data collection tools. "Classroom Engagement Inventory" was developed by Wang, Bergin and Bergin (2014), and adapted by Sever (2014) according to the Turkish Culture. Scale of Students' Attitudes towards Computer was developed by Teo (2008), and adapted by Demir and Yurdugül (2014) according to the Turkish Culture

\section{Data Analysis}

In the collected data, negative items were reversed and scored. Normality test, mean distribution, frequency and percentage analysis, standard deviation, independent sample t-test and related sample t-test were performed with the data collected from the scales. The whole scale and the comparative analyzes were interpreted as tables in the findings part of the research.

\section{FINDINGS}

In this research, "Classroom Engagement Inventory" and "Scale of Students' Attitudes towards Computer" were applied as pre-test and post-test before and after the course plan was applied. There was no significant difference in pretest scores of experimental and control groups.

At the end of the process, "Classroom Engagement Inventory" was applied to experimental and control groups. The mean posttest score of the experimental group was 3.06, the standard deviation was 1.16, the mean 
of posttest score of the control group was 2.50 and the standard deviation. .91. As a result of independent sample t-test, posttest scores of experimental group showed statistically significant difference from posttest scores of control group $(\mathrm{t}=.2 .18, \mathrm{p}<.05)$. $\mathrm{n}$ other words, it can be said that students who have coding education have higher level of attendance than students who have office program education. There was no significant difference between experimental and control groups' attitudes towards computer posttest scores.

\section{RESULT AND CONCLUSIONS}

At the end of the teaching process, it was concluded that the students' attitudes towards the computer and classroom engagement points did not change. The reason for this is thought to be a limited period of 8 weeks. These results are similar to those of the literature. Kasalak (2017) examined student experiences regarding robotic coding activities in his study. It was observed that the students had fun in the first weeks after the coding activities with Scratch and they were related but were bored at the end of the 4th week. In addition, Tekerek, Altan and Akdağ (2012) stated that the use of Scratch in the teaching of algorithms did not have a significant difference on students' learning.

When the pre-test and post-test results of the students studying in the office programs were examined, it was seen that affective participation scores to the computer course decreased. The reason for this is thought to be that the office programs generally include applications involving individual work, the teaching materials used are abstract, and the lack of appropriate teaching techniques for the timely completion of the teaching plan. As a result of the analysis, it was observed that the attitudes towards computer did not change. Küçük and Şişman (2016) examined the experiences of teachers in the coding course. According to the findings, it was observed that the interaction of the students with the robots increased the motivation of the students but did not affect their attitudes towards the lesson.

In general, attitudes towards computers did not change in both groups, but at the end of the process, it was observed that the affective participation of the group in which the office programs were given decreased. It can be said that the reason why the affective participation of the students who received training in coding was not affected negatively was due to concrete activities such as Arduino and Tinkercad. 